\title{
Immigration background and adolescent mental health problems: the role of family affluence, adolescent educational level and gender
}

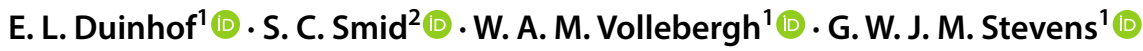

Received: 15 July 2019 / Accepted: 28 November 2019 / Published online: 14 January 2020

(c) The Author(s) 2020

\begin{abstract}
Purpose European studies demonstrated that immigrant adolescents are at a higher risk for mental health problems than native adolescents, but little is known about the role of socioeconomic status (SES) and gender in this association. This study examined to what extent differences in the mental health problems of non-western immigrant and native Dutch adolescents were explained by adolescents' family affluence and educational level and differed with the adolescents' family affluence, educational level, and gender.

Methods Adolescents in a Dutch nationally representative sample of 11-16-year old native Dutch $(n=5283)$ and non-western immigrants $(n=1054)$ reported on their family affluence, own educational level, conduct problems, emotional symptoms, peer relationship problems, and hyperactivity-inattention problems.

Results Non-western immigrant adolescents were at a higher risk for conduct problems and peer relationship problems than native Dutch adolescents, but family affluence and educational level explained only a very small proportion of these differences. With two exceptions, differences in the mental health problems of non-western immigrants and natives were highly comparable for different family affluence levels, educational levels, and for boys and girls. Only for natives, a higher family SES was related to less conduct problems. Furthermore, only for non-western immigrants a high family SES related to more hyperactivity-inattention problems.

Conclusions Our findings illustrate that the association between immigration background and adolescent mental health problems is largely independent of SES and gender. Future studies should include other factors to facilitate our understanding of the association between immigration background and adolescent mental health problems.
\end{abstract}

Keywords Adolescence $\cdot$ Mental health problems $\cdot$ Immigration background $\cdot$ Socioeconomic status $\cdot$ Gender

\section{Introduction}

In Europe, research addressing the association between immigration background and adolescent mental health problems generally supports a risk perspective, with immigrant

Electronic supplementary material The online version of this article (https://doi.org/10.1007/s00127-019-01821-8) contains supplementary material, which is available to authorized users.

E. L. Duinhof

e.1.duinhof@uu.nl

1 Department of Interdisciplinary Social Science, Faculty of Social and Behavioural Sciences, Utrecht University, P.O. Box 80.140, 3508 TC Utrecht, The Netherlands

2 Department of Methodology and Statistics, Faculty of Social and Behavioural Sciences, Utrecht University, P.O. Box 80.140, 3508 TC Utrecht, The Netherlands adolescents being at a higher risk of mental health problems than their native peers [1-4]. Several studies highlight that socioeconomic status (SES) is important to consider in such research because immigrant adolescents relatively often grow up in low SES families [e.g., 5]. Intersectionality theory [6] also highlights that the association between immigration background and adolescent mental health problems cannot be fully understood without acknowledging that adolescents belong to multiple, interconnected social groups (e.g., immigration background, SES, gender) and that these social group memberships jointly shape (mental) health outcomes $[7,8]$. However, studies explicitly testing the role of SES and gender in the association between immigration background and adolescent mental health problems are scarce. This is unfortunate, as an examination of the role of SES and gender may foster our understanding of the explanatory role of SES and help us identify those immigrant 
adolescents who are most at risk for mental health problems. This may inform intervention and prevention efforts aimed at reducing mental health disparities between immigrant and native adolescents. Therefore, this study investigated to what extent the association between immigration background and adolescent self-reported mental health problems (a) can be explained by the adolescents' family affluence and educational level and (b) differs with the adolescents' family affluence, educational level, or gender.

\section{The explanatory role of family SES and adolescent educational level}

Family SES and educational level may explain the association between immigration background and adolescent mental health problems. Research indicates that immigrant adolescents are less likely to grow up in affluent families [2, 9], less likely to attend higher educational tracks compared to natives [10], and both family SES and adolescent educational level are inversely related to adolescent mental health problems [11-13].

In Europe, studies mainly controlled for SES or examined the explanatory role of SES simultaneously with other family background variables. Studies testing the unique mediational pathways of family SES and educational level are thus rare. Moreover, those studies that focused on the explanatory role of family SES reported inconsistent results for different types of adolescent self-reported mental health problems. Overall, in Europe, family SES was found to (fully or partially) explain the association between immigration background and internalizing problems and social problems, but for externalizing problems results were inconsistent [2, 14]. For educational level even less empirical evidence is available. To our knowledge, only one study conducted in the Netherlands examined the explanatory role of adolescent educational level and found that educational level could not explain differences in mental health problems between immigrants and natives [14]. Hence, the explanatory role of family SES and educational level in the association between immigration background and different types of adolescent mental health problems remains poorly understood.

\section{The differential impact of family SES and adolescent educational level}

Family SES and educational level may also have a differential impact on the mental health problems of native and immigrant adolescents. According to the double jeopardy hypothesis [15], the effects of having an immigration background and a low SES will strengthen each other's impact. Immigrants encounter relatively many stressors (e.g., discrimination), which may deplete their coping resources and make them more vulnerable to additional stressors that are prevalent in low SES environments than natives $[16,17]$. Additionally, the combination of an immigration background and low SES might also result in a particularly unfavorable perceived social status [16]. If such perceptions of relative deprivation are seen as being unfair, they may lead to mental health problems [18]. Thus, due to the expected combined disadvantage of having an immigration background and a low SES, mental health gaps between native and immigrant adolescents may be greater for adolescents with a low than with a high SES.

In contrast, according to the diminishing returns hypothesis [19], attaining a higher SES may confer less mental health benefits to immigrant than native adolescents. Immigrant adolescents with a higher SES may perceive more discrimination than immigrant adolescents with a lower SES $[20,21]$ and, at the same time, they may receive less social support from other ethnic group members who may not perceive them as 'prototypical' ethnic group members anymore [22, 23]. Both processes might diminish the protective effect of a high SES for immigrant adolescents. From this perspective it may be inferred that mental health gaps between native and immigrant adolescents may be greater for adolescents with a high than with a low SES.

Studies examining the intersection of immigration background and SES are extremely scarce. Previous studies are almost exclusively conducted in the United States on adult samples and focused on family SES. The scarcely available literature revealed inconsistent findings for different types of adolescent self-reported mental health problems. For internalizing problems (e.g., depression), some studies found support for the double jeopardy hypothesis [17, 24], while others found support for the diminishing returns hypothesis [21,25], or did not find a differential impact of SES for native and immigrant adolescents [26]. The latter was also found for adolescent hyperactivity-inattention problems, externalizing problems and social problems [24]. Consequently, little (family SES) to nothing (adolescent educational level) is known about whether the association between immigration background and mental health problems depends upon the adolescents' SES.

\section{The differential impact of gender}

The association between immigration background and mental health problems may also differ for boys and girls. The intersectional invisibility hypothesis [27] argues that adolescents with multiple disadvantaged social group memberships do not fit the prototypes of the social group they belong to. To illustrate, the prototype of an immigrant is an immigrant boy and the prototype of a girl is a native girl. This may render adolescents with multiple disadvantaged social group memberships (i.e., immigrant girls), 'invisible' compared to their single disadvantaged peers (i.e., immigrant boys, native girls). 
Due to this 'intersectional invisibility' immigrant girls may experience distinct advantages (e.g., avoid more active forms of discrimination) and distinct disadvantages (e.g., experience invisibility discrimination) compared to their single disadvantaged peers.

In Europe, studies testing the intersection of immigration background and gender are relatively scarce and revealed inconsistent findings across different types of adolescent selfreported mental health problems. Some studies found that especially immigrant boys reported higher levels of internalizing problems $[28,29]$, and that immigrant girls-but not immigrant boys-reported higher levels of peer problems but lower levels of conduct problems than their native peers [30]. In contrast, other studies did not find gender differences in the association between immigration background and different types of adolescent self-reported mental health problems (e.g., internalizing problems, externalizing problems, peer relationship problems, hyperactivity-inattention problems) $[24,31$, 32]. Hence, it remains unclear whether immigrant boys or girls are more vulnerable for, different types of, mental health problems than native adolescents.

\section{This study}

Given the increasingly negative socio-political climate towards immigrants in the Netherlands [33, 34], it is highly relevant to examine the association between immigration background and adolescent mental health problems in the Dutch context. Using a nationally representative sample of 11-16-year old, native Dutch and non-western immigrant adolescents, the present study examined to what extent differences in a broad spectrum of self-reported mental health problems between immigrants and natives (a) can be explained by the adolescents' family affluence and educational level and (b) varied with the adolescents' family affluence, educational level, and gender. Since previous studies show that immigrant adolescents relatively often grow up in less affluent families and are overrepresented in lower educational tracks, family affluence and adolescent educational level were expected to-at least partly-explain the higher risk for mental health problems in immigrant adolescents. Although the literature is inconclusive about the direction, intersectionality theory $[6,7]$ assumes that the association between immigration background and adolescent mental health problems differs with the adolescents' family affluence, educational level and gender.

\section{Methods}

\section{Participants}

Data from the 2017 Dutch Health Behavior in Schoolaged Children (HBSC) study were used. HBSC is a cross-sectional, school-based survey that is conducted every 4 years in over 40 countries. Using a standardized research protocol, web-based, self-report questionnaires were administered to a nationally representative sample of adolescents in the classroom. Samples were drawn using cluster sampling, with schools being the primary sampling units. In the present study, adolescents attending primary education and special education were excluded.

The response rate on the school level was 37\%. Main reasons for non-response were participation in other surveys $(38 \%)$ or too frequent research participation requests (19\%). Additional analyses indicated no selection bias concerning immigration background or the number of students in the school. Only schools in urban areas were somewhat less likely to participate than schools in rural areas, which most likely stems from them getting more frequent research participation requests. Within randomly selected classes in these schools, the average response rate was $92 \%$ on the student level. Non-response was mostly due to absence because of illness or truancy. More information about the data collection can be found elsewhere [35]. Adolescents who did not fill in any of the items on mental health problems $(n=32)$ or immigration background $(n=1)$ were excluded from the sample.

In line with previous Dutch research [24], we focused on immigrant adolescents with a non-western immigration background. Since mass immigration to the Netherlands started from the 1960s in the last century predominantly from so-called non-western countries [33], non-western immigrants constitute by far the largest group of immigrant adolescents $(>70 \%)$. Studies show that non-western immigrant adolescents are especially likely to have a low SES $[36,37]$, and that the socio-cultural distance between the origin and receiving country is usually larger for immigrants originating from non-western than from western countries [38]. Therefore, we did not combine data from adolescents with a western and non-western immigration background.

The resulting final sample consisted of 6337 11-16 year old native Dutch and non-western immigrant adolescents. In our sample, adolescents with a non-western immigration background ( $n=1054)$ were mainly born in Morocco $(n=294,28 \%)$, Turkey $(n=173,16 \%)$, Suriname $(n=131$, $12 \%)$ and the Antilles $(n=60,6 \%)$ and belonged to the second generation (85.5\%) (i.e., they were born in the Netherlands, but at least one of their parents was born abroad).

\section{Measures}

\section{Mental health problems}

Adolescents filled in the Dutch translation of the problem scales of the Strengths and Difficulties Questionnaire (SDQ) [39], consisting of four subscales measuring mental 
health problems (conduct problems, emotional symptoms, peer relationship problems, hyperactivity-inattention problems). Each subscale includes five ordinal items with answer categories: 'Not true' $=0$, 'Somewhat true' $=1$; 'Certainly true' $=2$. The present study used a revised version of the problem scales: the SDQ-R [40]. Confirmatory factor analyses showed that the SDQ-R, that excluded the five reverse worded items of the original self-report SDQ, showed a better fit to the data than the original SDQ. The SDQ-R showed a good model fit $\left(\chi^{2}(84)=1168.67, p<0.001, \mathrm{CFI}=0.939\right.$, $\mathrm{TLI}=0.923$, RMSEA $=0.045)$, while the original SDQ did not demonstrate an acceptable model fit $\left(\chi^{2}(164)=2775.37\right.$, $p<0.001, \mathrm{CFI}=0.861, \mathrm{TLI}=0.839, \mathrm{RMSEA}=0.050)$.

Acceptable internal consistencies (ordinal $\alpha$ above 0.70) [41] were found for the conduct problems $(\alpha=0.74)$, emotional symptoms ( $\alpha=0.81)$, and hyperactivity-inattention problems $(\alpha=0.79)$ subscales of the SDQ-R. A somewhat lower internal consistency was found for the peer relationship problems subscale $(\alpha=0.63)$. Invariance tests indicated that the SDQ-R allowed for valid comparisons of mental health problems between natives and non-western immigrants, the three family affluence levels, the four educational levels, and boys and girls (see Online Resource 1). The Mplus syntax of all models testing the SDQ-R can be found on https://osf.io/cmga8/. In the final sample, the occurrence of missing values on the individual SDQ-R items ranged between $1(0.02 \%)$ and $21(0.3 \%)$.

\section{Demographic variables}

In line with previous international studies [e.g., 2], to measure immigration background, adolescents were asked to indicate the country of birth of both their parents. Following previous Dutch studies [24] and the definition of Statistics Netherlands, adolescents were considered having a non-western immigration background if at least one of their parents was born in a non-western country [Africa, Latin America, Asia (excluding Indonesia or Japan) and Turkey]. Adolescents of whom both parents were born in the Netherlands were considered having a native Dutch background. Age was assessed based upon the adolescents' month and year of birth and the date of the survey administration. Adolescents indicated their gender by responding to the question: 'Are you a boy or a girl?' with answer categories 'boy' and 'girl'. Adolescents also reported their educational level. In the Netherlands, secondary education consists of four different levels: low, medium, high prevocational education and pre-university education.

The Revised Family Affluence Scale (FAS) was used as a proxy for family SES. FAS is a valid indicator of family wealth and comprises six items on material assets in the family [42]. Examples of items are: 'Does your family own a car, van, or truck?' and 'Do you have your own bedroom for yourself?'. Responses were summed into a total FAS score. In line with previous studies [35], adolescent were identified as having a low (lowest 20\%), middle (middle 60\%), or high (highest 20\%) family affluence based upon the FAS distribution in the total sample. In the final sample, data on the FAS were missing for 106 (2\%) of the native Dutch and for 21 $(2 \%)$ of the non-western immigrant adolescents.

\section{Analytic strategy}

We conducted structural equation modelling analyses in Mplus version 8.2 [43] using the weighted least squares mean and variance-adjusted (WLSMV) estimator. Following recent recommendations on the SDQ [44], latent variable modeling was used to measure adolescent mental health problems. Analyses were corrected for cluster effects of adolescents in the same school (the primary sampling unit) and controlled for gender and age. To assure national representativeness, data were weighted for educational level, school grade, gender, and urbanicity. Given the large sample size, a stringent significance level was applied $(p<0.01)$. To examine the size of the associations between immigration background and adolescent mental health problems, standardized regression coefficients were interpreted using Cohen's $d$ [negligible $(d<0.20)$, small $(d=0.20-0.50)$, medium $(d=0.50-0.80)$, large $(d>0.80)$ ] [45].

Based on the literature, five different models were specified to test our hypotheses. First, the direct associations between immigration background and the four latent factors representing mental health problems were examined in the total sample (a graphical representation of Model 1 is displayed in Online Resource 2). Second, a mediation model was ran to examine if family affluence and adolescent educational level can explain differences in the mental health problems of native Dutch and non-western immigrant adolescents (Model 2). Since children growing up in higher SES families tend to have higher educational attainments [46, 47], a sequential two-mediator model with family affluence and adolescent educational level as ordinal mediators was examined (Fig. 1). With the WLSMV estimator a probit link function ${ }^{1}$ was used to model the coefficients for the regression paths with the ordinal mediators as outcome variables. To facilitate interpretation, probit regression probabilities were calculated (see Online Resource 3). All other regression paths can be interpreted as linear regression coefficients [43]. To compute the indirect effect of immigration background on adolescent mental health problems via family affluence and/or educational level, percentile bootstrapped

\footnotetext{
${ }^{1}$ Probit links are used to model categorical outcome variables, and transform the probabilities related to the outcome variables to standard normal $z$-scores [64].
} 


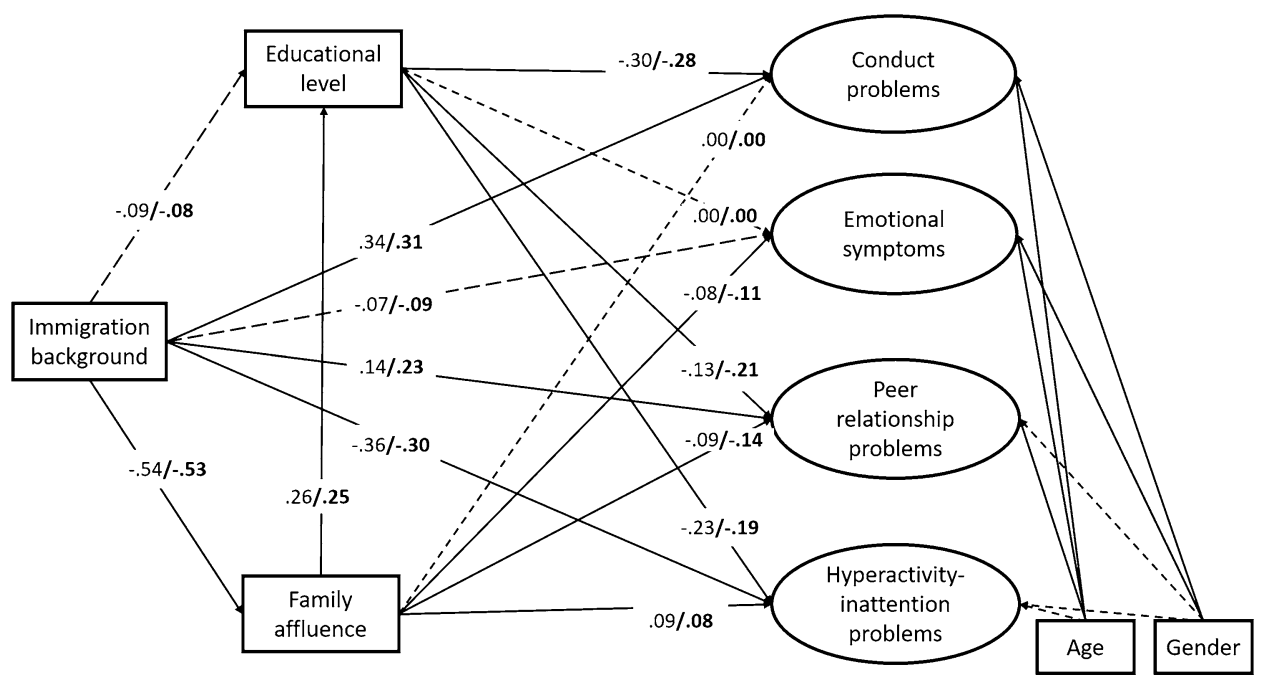

Fig. 1 Sequential two-mediator model showing the association between immigration background and adolescent mental health problems mediated by family affluence and educational level. Continuous lines indicate significant $(p<0.01)$ and dotted lines indicate non-significant $(p>0.01)$ regression coefficients. Non-bold numbers represent unstandardized and bold numbers represent standardized

confidence intervals (using 5000 replications) were obtained. Partially standardized effects were used to interpret the size of indirect effects [48].

Finally, three multigroup models (see Online Resource 2 for a graphical representation of the model tested in each subgroup) were tested to examine family affluence (Model 3), educational level (Model 4), and gender (Model 5) differences in the association between immigration background and adolescent mental health problems. The Wald test was used to test whether the associations between immigration background and adolescent mental health problems differed significantly between the three family affluence levels, four educational levels, and boys and girls. The Mplus syntax of all the five models can be found on https://osf.io/cmga8/.

\section{Results}

\section{Differences between the native Dutch and non-western immigrant adolescents}

Table 1 shows the family affluence, educational level, and gender distributions for the native Dutch and non-western immigrant adolescents. There were no significant differences in the age $(F(3.61,303.15)=0.45, p=0.75)$, gender $(F(1,84)=5.97, p=0.02)$, and educational level $(F(2.05$, $171.75)=1.48, p=0.23$ ) of both groups. Significant family affluence differences were found $(F(1.62,135.93)=48.87$, $p<0.001)$, with non-western immigrant adolescents reporting a lower family affluence than native Dutch adolescents. regression coefficients (using STD standardization, except for the probit regressions using STDY standardization). The rectangles represent observed variables and the ovals represent latent variables. To increase readability, latent factor indicators, (co)variances, and residual error terms were not modelled

Since measurement invariance was established (see Online Resource 1), latent means could be validly compared between the native Dutch and non-western immigrant adolescents. Table 2 shows that non-western immigrant adolescents reported more conduct problems and peer relationship problems, less hyperactivity-inattention problems and equal levels of emotional symptoms compared to native Dutch adolescents.

\section{The explanatory role of family affluence and adolescent educational level}

The sequential two-mediator model (Fig. 1) showed an acceptable fit to the data $\left(\chi^{2}(143)=1391.61, p<0.001\right.$, $\mathrm{CFI}=0.929, \mathrm{TLI}=0.907, \mathrm{RMSEA}=0.037)$ and explained a significant percentage of the variance in conduct problems $\left(R^{2}=0.12, p<0.001\right)$, emotional symptoms $\left(R^{2}=0.17, p\right.$ $<0.001)$, peer relationship problems $\left(R^{2}=0.11, p<0.001\right)$, and hyperactivity-inattention problems $\left(R^{2}=0.05, p\right.$ $<0.001)$.

Significant indirect effects were found for immigration background on emotional symptoms $(B=0.04, \beta=0.06$, $99 \%$ CI $[0.02,0.07])$, peer relationship problems $(B=0.05$, $\beta=0.08,99 \% \mathrm{CI}[0.02,0.08])$, and hyperactivity-inattention problems $(B=-0.05, \beta=-0.04,99 \% \mathrm{CI}[-0.09,-0.01])$ through family affluence. No indirect effect was found for immigration background on conduct problems $(B=-0.00$, $\beta=-0.00,99 \%$ CI $[-0.04,0.03])$ via family affluence. Being a non-western immigrant (compared to native Dutch) resulted in an increase in emotional symptoms, an increase 
Table 1 Demographic statistics of the native Dutch and nonwestern immigrant adolescents

\begin{tabular}{lcc}
\hline & $\begin{array}{l}\text { Native Dutch } \\
(n=5283)\end{array}$ & $\begin{array}{l}\text { Non-western } \\
\text { immigrant } \\
(n=1054)\end{array}$ \\
\hline Age, $M(\mathrm{SD})$ & $13.92(1.40)$ & $14.00(1.37)$ \\
Gender, $n$ (weighted \%) & $2594(52.0)$ & $473(47.1)$ \\
Boys & $2689(48.0)$ & $581(52.9)$ \\
Girls & $846(17.0)$ & $222(23.0)$ \\
Educational level, $n$ (weighted \%) & $1541(27.4)$ & $358(33.6)$ \\
Low prevocational education & $1384(26.8)$ & $209(19.0)$ \\
Medium prevocational education & $1512(28.7)$ & $265(24.5)$ \\
High prevocational education & & $359(35.6)$ \\
Pre-university education & $853(16.4)$ & $542(52.2)$ \\
Family affluence, $n$ (weighted \%) & $3106(59.8)$ & $132(12.2)$ \\
Low & $1218(23.8)$ & \\
Middle & & \\
High & & \\
\hline
\end{tabular}

$n$ represent the unweighted number of participants; \% represent the percentages weighted for educational level, school grade, gender, and urbanicity

Table 2 Immigration background and adolescent self-reported mental health problems

\begin{tabular}{|c|c|c|c|c|c|c|c|c|c|c|c|c|}
\hline & \multicolumn{3}{|c|}{ Conduct problems } & \multicolumn{3}{|c|}{ Emotional symptoms } & \multicolumn{3}{|c|}{$\begin{array}{l}\text { Peer relationship } \\
\text { problems }\end{array}$} & \multicolumn{3}{|c|}{$\begin{array}{l}\text { Hyperactivity-inattention } \\
\text { problems }\end{array}$} \\
\hline & $B$ & SE & $\beta$ & $B$ & SE & $\beta$ & $B$ & SE & $\beta$ & $B$ & SE & $\beta$ \\
\hline Immigration background & $0.28^{*}$ & 0.04 & 0.36 & -0.03 & 0.02 & -0.04 & $0.21 *$ & 0.03 & 0.39 & $-0.22 *$ & 0.04 & -0.29 \\
\hline
\end{tabular}

Reference category $=$ native Dutch adolescents

$* p<0.001$

in peer relationship problems, but a decrease in hyperactivity-inattention problems through changes in family affluence. Non-western immigrant adolescents were less likely to report a high family affluence than native Dutch adolescents (Online Resource 3). Adolescents in more affluent families reported somewhat lower levels of emotional symptoms and peer relationship problems but somewhat higher levels of hyperactivity-inattention problems (Fig. 1).

No significant indirect effects were found for immigration background on conduct problems $(B=0.03, \beta=0.02$, $99 \%$ CI $[-0.08,0.14])$, emotional symptoms $(B=0.00$, $\beta=0.00,99 \%$ CI $[-0.01,0.01])$, peer relationship problems $(B=0.01, \beta=0.02$, 99\% CI $[-0.04,0.06])$, and hyperactivity-inattention problems $(B=0.02, \beta=0.02$, 99\% CI [- 0.07, 0.10]) through adolescent educational level. Results did however indicate a significant indirect effect of immigration background on conduct problems $(B=0.04, \beta=0.04,99 \% \mathrm{CI}[0.02,0.07])$, peer relationship problems $(B=0.02, \beta=0.03,99 \%$ CI $[0.01,0.03])$, and hyperactivity-inattention problems $(B=0.03, \beta=0.03$, $99 \%$ CI $[0.02,0.05])$ via family affluence and adolescent educational level. No indirect effect was found for immigration background on emotional symptoms $(B=0.00$, $\beta=0.00,99 \% \mathrm{CI}[-0.01,0.01])$ via family affluence and adolescent educational level. Being an non-western immigrant (compared to native Dutch) resulted in an increase in conduct problems, peer relationship problems, and hyperactivity-inattention problems through changes in the adolescents' family affluence and educational level. Compared to native Dutch adolescents, non-western immigrant adolescents were less likely to report high levels of family affluence. Native Dutch and non-western immigrant adolescents in highly affluent families were more likely to attend higher educational levels (Online Resource 3). Adolescents attending higher educational levels reported lower levels of conduct problems, peer relationship problems, and hyperactivity-inattention problems (Fig. 1).

All indirect effects were fairly small in size. Furthermore, comparing the model without family affluence and educational level (Table 2) with the mediation model including family affluence and educational level (Fig. 1), non-western immigrants still reported more conduct problems and peer relationship problems, less hyperactivity-inattention problems and equally high levels of emotional symptoms as their native Dutch peers. 


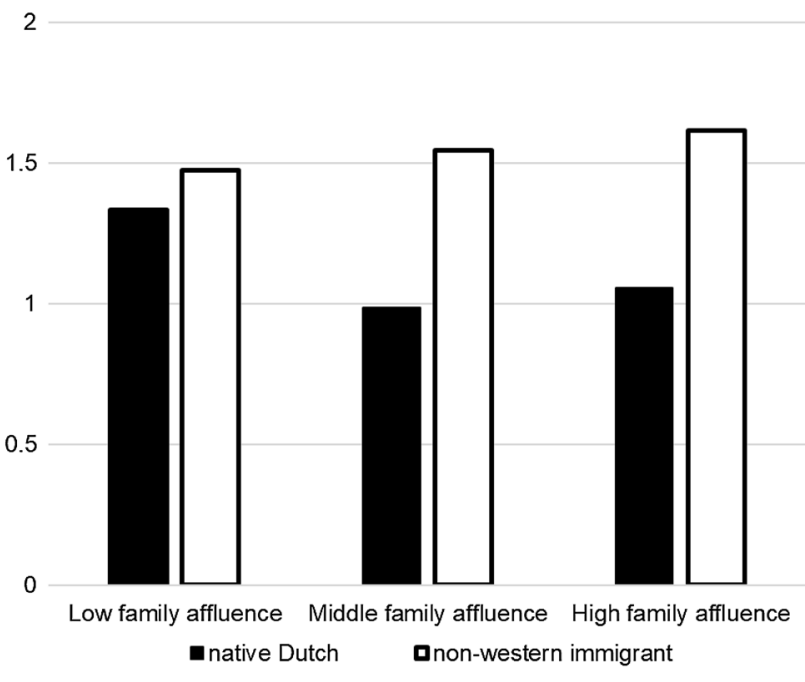

Fig. 2 Differences in conduct problems between native Dutch and non-western immigrant adolescent in low, middle and high affluent families

\section{The differential impact of family affluence and adolescent educational level}

The association between immigration background and conduct problems (Wald $\chi^{2}(2)=11.14, p=0.004$ ) and hyperactivity-inattention problems (Wald $\chi^{2}(2)=12.31$, $p=0.002$ ) differed across family affluence levels. In contrast, the associations between immigration background and emotional symptoms (Wald $\chi^{2}(2)=2.37, p=0.31$ ) and peer relationship problems (Wald $\chi^{2}(2)=3.06, p=0.22$ ) were equal across family affluence levels. In families with relatively low levels of affluence, non-western immigrant adolescents reported equal levels of conduct problems $(B=0.10$, $\beta=0.13, p=0.11,99 \%$ CI $[-0.06,0.26])$ as native Dutch adolescents, whereas in families with middle $(B=0.37$, $\beta=0.45, p<0.001,99 \%$ CI $[0.21,0.52])$ and high $(B=0.36$, $\beta=0.44, p<0.001,99 \%$ CI $[0.10,0.61])$ levels of affluence, non-western immigrant adolescents reported higher levels of conduct problems than native Dutch adolescents. Family affluence did not impact the level of conduct problems of non-western immigrant adolescents, while middle or high levels of family affluence decreased the conduct problems for native Dutch adolescents compared to a low family affluence (Fig. 2).

In addition, in families with low $(B=-0.29, \beta=-0.40$, $p<0.001,99 \%$ CI $[-0.46,-0.13])$ and middle $(B=-0.22$, $\beta=-0.30, p<0.001,99 \%$ CI $[-0.35,-0.09])$ levels of affluence non-western immigrant adolescents reported lower levels of hyperactivity-inattention problems than native Dutch adolescents, whereas in highly affluent families $(B=0.05, \beta=0.07, p=0.53,99 \% \mathrm{CI}[-0.15,0.25])$ equal levels of hyperactivity-inattention problems were reported

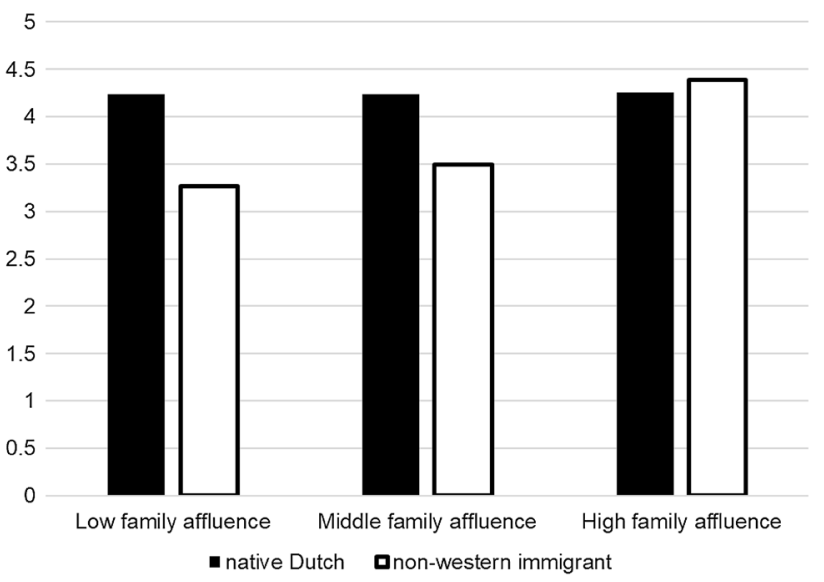

Fig. 3 Differences in hyperactivity-inattention problems between native Dutch and non-western immigrant adolescent in low, middle and high affluent families

by both groups. Figure 3 shows that family affluence was not related to the hyperactivity-inattention problems in native Dutch adolescents, while for non-western immigrant adolescents, high levels of family affluence increased their hyperactivity-inattention problems compared to low and middle levels of family affluence.

No educational level differences were found in the association between immigration background and adolescent mental health problems. The association between immigration background and conduct problems (Wald $\chi^{2}(3)=4.52, p=0.21$ ), emotional symptoms (Wald $\chi^{2}(3)=0.44, p=0.93$ ), peer relationship problems (Wald $\chi^{2}(3)=7.47, p=0.06$ ), and hyperactivity-inattention problems (Wald $\chi^{2}(3)=7.07, p=0.07$ ) was similar across all four educational levels.

\section{The differential impact of gender}

The association between immigration background and adolescent mental health problems did also not vary with the gender of the adolescent. Associations between immigration background and conduct problems (Wald $\chi^{2}(1)=2.48$, $p=0.12$ ), emotional symptoms (Wald $\chi^{2}(1)=1.70$, $p=0.19$ ), peer relationship problems (Wald $\chi^{2}(1)=4.20$, $p=0.04$ ), and hyperactivity-inattention problems (Wald $\chi^{2}$ $(1)=4.30, p=0.04$ ) were equal for boys and girls.

\section{Discussion}

It has been theorized-but rarely explicitly examined - that SES and gender play an important role in the association between immigration background and adolescent mental health problems. Interestingly, the result of this study illustrate that the association between immigration background 
and adolescent mental health problems is largely independent of SES and gender. First, although non-western immigrant adolescents were less likely to grow up in highly affluent families, this explained only a very small proportion of their higher risk for conduct problems and peer relationship problems compared to the native Dutch adolescents. Second, these differences in mental health problems were quite robust across family affluence levels, educational levels and boys and girls. Only two interactions were revealed: for native Dutch adolescents higher levels of family affluence were associated with less conduct problems, while there was no association between family affluence and conduct problems for non-western immigrants. No association between family affluence and hyperactivity-inattention problems was revealed for native Dutch adolescents, while for non-western immigrants a high level of family affluence was associated with more hyperactivity-inattention problems.

Studies testing the unique mediational pathways of family SES and educational level in the association between immigration background and adolescent mental health problems are rare. Using advanced statistical methods, we were able to model the association between family affluence and adolescent educational level [e.g., 46] and to test the explanatory role of family affluence and adolescent educational level alone and together. Our finding that immigration background had an indirect effect on adolescent internalizing problems (i.e., emotional symptoms) and social problems (i.e., peer relationship problems), but not on externalizing problems (i.e., conduct problems) via family affluence is largely in line with previous studies [2, 14]. However, the size of these indirect effects was very small, which may be due to the weak association between family affluence and adolescent mental health problems. In a high income country like the Netherlands, low levels of family affluence may still reflect relatively high material living standards. Therefore, adolescents may have few material desires [49], which may diminish the impact of family affluence on adolescent mental health problems. Alternatively, the Dutch universal health care system that provides health care allowances for low income families may explain the weak associations found between family affluence and adolescent mental health problems.

In line with former results [14], adolescent educational level did not explain differences in mental health problems between non-western immigrant and native Dutch adolescents either. This is not surprising as there were no educational level differences between non-western immigrant and native Dutch adolescents. Although, via family affluence, adolescent educational level had some explanatory power, again the size of these indirect effects was fairly small. Thus, in the Netherlands, other factors than SES may explain the higher risk for conduct problems and peer relationship problems of non-western immigrant adolescents.
Given increasingly negative attitudes towards immigrants in Europe [50], and evidence of an increasingly negative sociopolitical climate towards immigrants in the Netherlands [33, 34], perceptions of discrimination may be a relevant factor.

Although intersectionality theory [6] clearly emphasizes the need to study the intersections of adolescents' social group memberships (e.g., immigration background, SES, gender), studies examining the role of SES and gender in the link between immigration background and adolescent mental health problems are scarce, especially in Europe [51]. Contributing to the scarce and inconsistent literature [e.g., 17, 21, 24, 25], our results indicated that differences in mental health problems between non-western immigrant and native Dutch adolescents were largely comparable for different family affluence and educational levels. This was also the case for gender differences, which is in line with previous Dutch studies [24, 31]. Two (out of a possible twelve) interactions between immigration background and family affluence were found, however.

Supporting the diminishing returns hypothesis, only for native Dutch adolescents higher levels of family affluence were associated with less conduct problems. Immigrants with a higher SES may be more aware of discrimination [52] and such perceptions of discrimination may diminish the protective effect of a high family SES for immigrant adolescents [21]. However, this effect was only found for conduct problems and not robust over the whole spectrum of adolescent mental health problems.

For hyperactivity-inattention problems findings at first seemed counterintuitive. Non-western immigrants reported lower levels of hyperactivity-inattention problems than their native peers and high levels of family affluence increased the hyperactivity-inattention problems of non-western immigrant adolescents only. Studies show that higher SES immigrants have more contacts with natives than lower SES immigrants [52,53] and that Dutch adolescents report relatively high levels of hyperactivity-inattention problems compared to their European agemates [40]. Due to influence processes [54], immigrant adolescents in higher SES families-who are assumed to have more contacts with native peers-may become more similar in their behavior and/or attitudes towards hyperactive and inattentive behavior to native peers and report higher levels of hyperactivity-inattention problems.

Using a nationally representative sample of Dutch adolescents, two indicators of SES (family affluence and adolescent educational level), a broad spectrum of adolescent mental health problems, and a rigorous methodological design, this study showed that the role of SES and gender in the association between immigration background and adolescent mental health problems is at best small. Still, some limitations and alternative explanations of our findings should be considered. First, the cross-sectional nature of our data 
does not allow for causal inferences about the explanatory role of SES. Our findings suggest that higher SES environments may protect against mental health problems. However, the opposite may also be true; mental health problems may negatively impact adolescents' educational careers [47]. Second, although by establishing measurement invariance we made sure that the native Dutch and non-western immigrant adolescents did not systematically differ in their responses on the mental health problems measures, we cannot rule out that cultural differences in socialization practices may have contributed to differences in the mental health problems of the non-western immigrant and native Dutch adolescents [55].

Third, the HBSC study is designed to gather a nationally representative sample of Dutch adolescents. This is a clear advantage as our findings are generalizable to the overall population of Dutch adolescents. However, our sample design did not allow for analyses stratified by specific immigrant group characteristics (i.e., country of origin, generational status, reasons for immigration). It remains to be seen whether this has sizeable consequences for our results, as previous Dutch studies that distinguished between immigrants with specific ethnic backgrounds found highly similar mental health differences in the different immigrant groups [56-58]. Also, in Europe, evidence for an immigration paradox (suggesting that later generations immigrants are doing worse than earlier generations) is much less convincing than in the United States [2, 59-62]. Notwithstanding these former findings, future studies testing the generalizability of our results in a broad scale of specific immigrant groups from different countries of origin (including western countries), different generational statuses, and with different reasons for immigration (e.g., labor, refugees) are highly relevant. Fourth, our questionnaire was only available in the Dutch language. For a small group of immigrant adolescents, especially those from the first generation who recently immigrated to the Netherlands, a language barrier may have impacted their self-reports. Finally, in this study we only used one measure of family SES; family affluence. Studies show that the association between family SES and adolescent mental health problems may vary with the operationalization of family SES [11]. However, given that especially for younger adolescents it is difficult to report on their parents' occupation and educational level or family income, adolescents' reports of family affluence provide a particularly reliable measure of family SES [63].

\section{Conclusion}

With non-western immigrant adolescents only reporting higher levels of conduct problems and peer relationship problems, our study does not unequivocally support the risk perspective of immigration [1-3]. The risk perspective of immigration may thus vary with the type of mental health problems. Family affluence and adolescent educational level could not explain the higher risk of conduct problems and peer relationship problems of non-western immigrant adolescents compared to native Dutch adolescents. Even more, these differences in mental health problems were quite robust across different family affluence levels, adolescent educational levels, and between boys and girls. Thus, although it is theorized that SES and gender play an important role in the association between immigration background and adolescent mental health problems, our findings indicate that in the Netherlands the role of SES and gender is limited.

Taken together, our results imply that not only immigrant adolescents from low SES backgrounds, but immigrants (both boys and girls) from a wide range of SES backgrounds may need prevention and intervention programs targeting their mental health, specifically concerning conduct problems and peer relationship problems. Future studies should test whether other factors-such as perceptions of discrimination - may account for differences in the mental health of immigrant and native adolescents. Moreover, internationally comparative research examining the intersection of immigration background with SES and gender is needed to examine the generalizability of our findings outside the Netherlands and to map mental health inequalities between immigrant and native adolescents with more precision.

Acknowledgements S. C. Smid was supported by a Grant from the Netherlands organization for scientific research: NWO-VIDI-452-14-006.

\section{Compliance with ethical standards}

Conflict of interest The authors declare that they have no conflict of interest.

Ethical standards This study has been approved by the ethics committee of the Faculty of Social and Behavioral Sciences of Utrecht University (FETC17-079). All adolescents gave active informed consent prior to inclusion in the study.

Open Access This article is licensed under a Creative Commons Attribution 4.0 International License, which permits use, sharing, adaptation, distribution and reproduction in any medium or format, as long as you give appropriate credit to the original author(s) and the source, provide a link to the Creative Commons licence, and indicate if changes were made. The images or other third party material in this article are included in the article's Creative Commons licence, unless indicated otherwise in a credit line to the material. If material is not included in the article's Creative Commons licence and your intended use is not permitted by statutory regulation or exceeds the permitted use, you will need to obtain permission directly from the copyright holder. To view a copy of this licence, visit http://creativecommons.org/licenses/by/4.0/. 


\section{References}

1. Dimitrova R, Chasiotis A, Van de Vijver F (2016) Adjustment outcomes of immigrant children and youth in Europe: a metaanalysis. Eur Psychol 21:150-162

2. Stevens GWJM, Walsh SD, Huijts T, Maes M, Madsen KR, Cavallo F, Molcho M (2015) An internationally comparative study of immigration and adolescent emotional and behavioral problems: effects of generation and gender. J Adolesc Health 57:587-594

3. Mock-muñoz de Luna CJ, Vitus K, Torslev MK, Krasnik A, Jervelund SS (2019) Ethnic inequalities in child and adolescent health in the Scandinavian welfare states: the role of parental socioeconomic status - a systematic review. Scand J Public Health 47:679-689

4. McMahon EM, Corcoran P, Keeley H et al (2017) Mental health difficulties and suicidal behaviours among young migrants: multicentre study of European adolescents. Br J Psychiatry Open 3:291-299

5. Dogra N, Singh SP, Svirydzenka N, Vostanis P (2012) Mental health problems in children and young people from minority ethnic groups: the need for targeted research. Br J Psychiatry 200:265-267

6. Crenshaw K (1989) Demarginalizing the intersection of race and sex: a black feminist critique of antidiscrimination doctrine, feminist theory and antiracist politics. Univ Chic Leg Forum 1989:8

7. Cole ER (2009) Intersectionality and research in psychology. Am Psychol 64:170-180

8. Else-Quest NM, Hyde JS (2016) Intersectionality in quantitative psychological research: I. Theoretical and epistemological issues. Psychol Women Q 40:155-170

9. Molcho M, Cristini F, Gabhainn SN et al (2010) Health and wellbeing among child immigrants in Europe. Eurohealth 16:20-23

10. Alba R, Sloan J, Sperling J (2011) The integration imperative: the children of low-status immigrants in the schools of wealthy societies. Annu Rev Sociol 37:395-418

11. Reiss F (2013) Socioeconomic inequalities and mental health problems in children and adolescents: a systematic review. Soc Sci Med 90:24-31

12. Havas J, Bosma H, Spreeuwenberg C, Feron FJ (2009) Mental health problems of Dutch adolescents: the association with adolescents' and their parents' educational level. Eur J Public Health 20:258-264

13. Klanšček HJ, Ziberna J, Korošec A, Zurc J, Albreht T (2014) Mental health inequalities in Slovenian 15-year-old adolescents explained by personal social position and family socioeconomic status. Int J Equity Health 13:26

14. Murad DS, Joung IMA, van Lenthe FJ, Bengi-Arslan L, Crijnen AAM (2003) Predictors of self-reported problem behaviours in Turkish immigrant and Dutch adolescents in the Netherlands. J Child Psychol Psychiatry 44:412-423

15. Dowd JJ, Bengtson VL (1978) Aging in minority populations an examination of the double jeopardy hypothesis. J Gerontol $33: 427-436$

16. Mcleod JD, Owens TJ (2004) Psychological well-being in the early life course: variations by socioeconomic status, gender, and race/ethnicity. Soc Psychol Q 67:257-278

17. Adkins DE, Wang V, Dupre ME, van den Oord JCG, Elder GH (2009) Structure and stress: trajectories of depressive symptoms across adolescence and young adulthood. Soc Forces 88:31-60

18. Smith HJ, Pettigrew TF, Pippin GM, Bialosiewicz S (2012) Relative deprivation: a theoretical and meta-analytic review. Personal Soc Psychol Rev 16:203-232

19. Farmer MM, Ferraro KF (2005) Are racial disparities in health conditional on socioeconomic status? Soc Sci Med 60:191-204
20. Turcatti D (2018) The educational experiences of Moroccan Dutch youth in the Netherlands: place-making against a backdrop of racism, discrimination and inequality. Intercult Educ 00:1-16

21. Cheng ER, Cohen A, Goodman E (2015) The role of perceived discrimination during childhood and adolescence in understanding racial and socioeconomic influences on depression in young adulthood. J Pediatr 166:370-377

22. Johnson JD, Kaiser CR (2012) Racial identity denied: are wealthy black victims of racism rejected by their own group? Soc Psychol Personal Sci 4:376-382

23. Cole ER, Omari SR (2003) Race, class and the dilemmas of upward mobility for African Americans. J Soc Issues 59:785-802

24. Vollebergh WAM, ten Have M, Dekovic M et al (2005) Mental health in immigrant children in the Netherlands. Soc Psychiatry Psychiatr Epidemiol 40:489-496

25. Jackson B, Goodman E (2011) Low social status markers: do they predict depressive symptoms in adolescence? Race Soc Probl 3:119-128

26. Evans CR, Erickson N (2019) Intersectionality and depression in adolescence and early adulthood: a MAIHDA analysis of the national longitudinal study of adolescent to adult health, 19952008. Soc Sci Med 220:1-11

27. Purdie-Vaughns V, Eibach RP (2008) Intersectional invisibility: the distinctive advantages and disadvantages of multiple subordinate-group identities. Sex Roles 59:377-391

28. Fandrem H, Sam DL, Roland E (2009) Depressive symptoms among native and immigrant adolescents in Norway: the role of gender and urbanization. Soc Indic Res 92:91-109

29. Oppedal B, Røysamb E (2004) Mental health, life stress and social support among young Norwegian adolescents with immigrant and host national background. Scand J Psychol 45:131-144

30. Alonso-fernández N, Jiménez-García R, Alonso-fernández L, Hernández-Barrera V, Palacios-ceña D (2017) Mental health and quality of life among spanish-born and immigrant children in years 2006 and 2012. J Pediatr Nurs 36:103-110

31. Stevens GWJM, Pels T, Bengi-Arslan L, Verhulst FC, Vollebergh WAM, Crijnen AAM (2003) Parent, teacher and self-reported problem behavior in The Netherlands: comparing Moroccan immigrant with Dutch and with Turkish immigrant children and adolescents. Soc Psychiatry Psychiatr Epidemiol 38:576-585

32. Steinhausen H-C, Bearth-Carrari C, Winkler Metzke C (2009) Psychosocial adaptation of adolescent migrants in a Swiss community survey. Soc Psychiatry Psychiatr Epidemiol 44:308-316

33. Geddes A, Scholten P (2016) The Netherlands: beyond multiculturalism? In: Geddes A, Scholten P (eds) The politics of migration and immigration in Europe. SAGE Publications Ltd, Thousand Oaks, pp 101-124

34. Thijs P, te Grotenhuis M, Scheepers P (2018) The paradox of rising ethnic prejudice in times of educational expansion and secularization in the Netherlands, 1985-2011. Soc Indic Res 139:653-678

35. Inchley J, Currie D, Young T et al (2016) Growing up unequal: gender and socioeconomic differences in young people's health and well-being: health behaviour in school-aged children (HBSC) study: International Report from the 2013/2014 Survey. WHO Regional Office for Europe, Copenhagen

36. Dutch Inspectorate of Education (2018) Summary report: the state of education in the Netherlands 2016/2017. Netherlands Inspectorate of Education, Utrecht

37. Hoff S, van Hulst B, Wildeboer Schut JM, Goderis B (2019) Summary: Poverty Survey 2019. The Netherlands Institute for Social Research, Hague

38. Kalmijn M (2015) The children of intermarriage in four European countries: implications for school achievement, social contacts, and cultural values. Ann Am Acad Polit Soc Sci 662:246-265 
39. Goodman R (1997) The strengths and difficulties questionnaire: a research note. J Child Psychol Psychiatry 38:581-586

40. Duinhof EL, Lek KM, de Looze ME et al (2020) Revising the selfreport strengths and difficulties questionnaire for cross-country comparisons of adolescent mental health problems: the SDQ-R. Epidemiol Psychiatr Sci 29:e35

41. Gadermann AM, Guhn M, Zumbo BD (2012) Estimating ordinal reliability for Likert-type and ordinal item response data: a conceptual, empirical, and practical guide. Pract Assess Res Eval 17:1-13

42. Torsheim T, Cavallo F, Levin KA et al (2016) Psychometric validation of the revised family affluence scale: a latent variable approach. Child Indic Res 9:771-784

43. Muthén LK, Muthén BO (2017) User's guide, 8th edn. Muthén \& Muthén, Los Angeles

44. Smid SC, Hox JJ, Heiervang ER, Stormark KM, Hysing M, Bøe T (2018) Measurement equivalence and convergent validity of a mental health rating scale. Assessment. https://doi. org/10.1177/1073191118803159

45. Cohen J (1988) Statistical power analysis for the behavioral sciences, 2nd edn. Lawrence Erlbaum Associates, Hillsdale

46. Melby JN, Conger RD, Fang SA, Wickrama KAS, Conger KJ (2008) Adolescent family experiences and educational attainment during early adulthood. Dev Psychopathol 44:1519-1536

47. Conger RD, Conger KJ, Martin MJ (2010) Socioeconomic status, family processes, and individual development. J Marriage Fam 72:685-704

48. Miočević M, O’Rourke HP, MacKinnon DP, Brown HC (2018) Statistical properties of four effect-size measures for mediation models. Behav Res Methods 50:285-301

49. Maslow AH (1943) A theory of human motivation. Psychol Rev 50:370-396

50. Ceobanu AM, Escandell X (2010) Comparative analyses of public attitudes toward immigrants and immigration using multinational survey data: a review of theories and research. Annu Rev Sociol 36:309-328

51. Ghavami N, Katsiaficas D, Rogers LO (2016) Toward an intersectional approach in developmental science: the role of race, gender, sexual orientation, and immigrant status. Adv Child Dev Behav 50:31-73

52. Verkuyten $M$ (2016) The integration paradox: empiric evidence from the Netherlands. Am Behav Sci 60:583-596
53. Martinović B (2013) The inter-ethnic contacts of immigrants and natives in the Netherlands: a two-sided perspective. J Ethn Migr Stud 39:69-85

54. Veenstra R, Dijkstra JK, Steglich C, Van Zalk MHW (2013) Network-behavior dynamics. J Res Adolesc 23:399-412

55. Weisz JR, Suwanlert S, Chaiyasit W, Walter BR (1987) Over- and undercontrolled referral problems among children and adolescents From Thailand and the United States: the wat and wai of cultural differences. J Consult Clin Psychol 55:719-726

56. Adriaanse M, Veling W, Doreleijers T, van Domburgh L (2014) The link between ethnicity, social disadvantage and mental health problems in a school-based multiethnic sample of children in the Netherlands. Eur Child Adolesc Psychiatry 23:1103-1113

57. Zwirs BWC, Burger H, Schulpen TWJ, Buitelaar JK (2006) Different treatment thresholds in non-western children with behavioral problems. J Am Acad Child Adolesc Psychiatry 45:476-483

58. Bevaart F, Mieloo CL, Jansen W, Raat H, Donker MCH, Verhulst FC, van Oort FVA (2012) Ethnic differences in problem perception and perceived need for care for young children with problem behaviour. J Child Psychol Psychiatry 53:1063-1071

59. Mood C, Jonsson JO, Laftman SB (2016) Immigrant integration and youth mental health in four European countries. Eur Sociol Rev 32:716-729

60. Sam DL, Vedder P, Liebkind K, Neto F, Virta E (2008) Immigration, acculturation and the paradox of adaptation in Europe. Eur J Dev Psychol 5:138-158

61. Marks AK, Ejesi K, García Coll C (2014) Understanding the US immigrant paradox in childhood and adolescence. Child Dev Perspect 8:59-64

62. Garcia Coll C, Patton F, Marks AK, Dimitrova R, Yang H, Suarez GA, Patricio A (2012) Understanding the immigrant paradox in youth: developmental and contextual considerations. In: Masten AS, Liebkind K, Hernandez DJ (eds) Capitalizing on migration. The potential of immigrant youth. Cambridge University Press, New York, pp 159-180

63. Currie C, Molcho M, Boyce W, Holstein B, Torsheim T, Richter M (2008) Researching health inequalities in adolescents: the development of the Health Behaviour in School-Aged Children (HBSC) Family Affluence Scale. Soc Sci Med 66:1429-1436

64. Agresti A (2018) An introduction to categorical data analysis. Wiley, New York 